\title{
Does hormonal contraception during molar pregnancy follow-up influence the risk and clinical aggressiveness of gestational trophoblastic neoplasia after controlling for risk factors?
}

\author{
Patrícia Rangel Sobral Dantas ${ }^{\mathrm{a}, \mathrm{b}}$, Izildinha Maestá a , Jorge Rezende Filho ${ }^{\mathrm{b}, \mathrm{c}}$, Joffre Amin Junior ${ }^{\mathrm{b}, \mathrm{c}}$, \\ Kevin M. Elias ${ }^{\mathrm{d}}$, Neil Howoritz ${ }^{\mathrm{d}}$, Antonio Braga ${ }^{\mathrm{b}, \mathrm{c}, \mathrm{e}, *}$, Ross S. Berkowitz ${ }^{\mathrm{d}}$

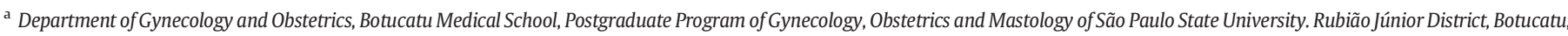 \\ São Paulo, Brazil \\ ${ }^{\mathrm{b}}$ Rio de Janeiro Trophoblastic Disease Center, Brazilian Association of Gestational Trophoblastic Disease, 180 Laranjeiras St, Laranjeiras, Rio de Janeiro, RJ, Brazil

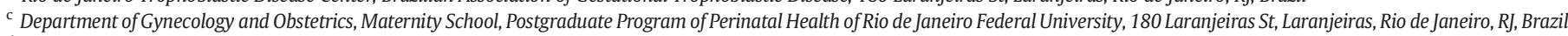

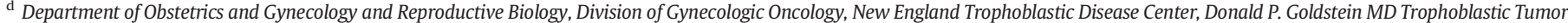 \\ Registry, Brigham and Women's Hospital, Dana-Farber Cancer Institute, Harvard Medical School, 75 Francis St, Boston, MA, USA

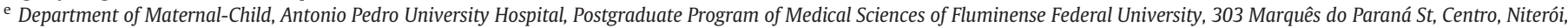 \\ Rio de Janeiro, Brazil
}

\section{H I G H L I G H T S}

- Hormone contraception does not increase the risk of gestational trophoblastic neoplasia.

- Hormone contraception does not alter severity of gestational trophoblastic neoplasia.

- Hormone contraception does not delay hCG regression.

\section{A R T I C L E I N F O}

\section{Article history:}

Received 8 August 2017

Received in revised form 7 September 2017

Accepted 9 September 2017

Available online 18 September 2017

\section{Keywords:}

Molar pregnancy

Contraception

Gestational trophoblastic neoplasia

\section{A B S T R A C T}

Objective. To evaluate the influence of hormonal contraception (HC) on the development and clinical aggressiveness of gestational trophoblastic neoplasia (GTN) and the time for normalization of human chorionic gonadotropin (hCG) levels.

Methods. A retrospective cohort study was conducted with women diagnosed with molar pregnancy, followed at the Rio de Janeiro Trophoblastic Disease Center, between January 2005 and January 2015. The occurrence of postmolar GTN and the time for hCG normalization between users of HC or barrier methods (BM) during the postmolar follow-up or GTN treatment were evaluated.

Results. Among 2828 patients included in this study, 2680 (95\%) used HC and 148 (5\%) used BM. The use of HC did not significantly influence the occurrence of GTN (ORa: 0.66, 95\% CI: 0.24-1.12, p = 0.060), despite different formulations: progesterone-only (ORa: 0.54, 95\% CI: 0.29-1.01, p = 0.060) or combined oral contraception (COC) (ORa: $0.50,95 \% \mathrm{Cl}: 0.27-1.01, \mathrm{p}=0.60$ ) or with different dosages of ethinyl estradiol: $15 \mathrm{mcg}$ (ORa, 1.33, 95\% CI 0.79-2.24, p = 0.288), 20 mcg (ORa: 1.02, 95\% CI: 0.64-1.65, p = 0.901), 30 mcg (ORa: 1.17, 95\% CI: $0.78-1.75, p=0.437$ ) or $35 \mathrm{mcg}$ (ORa: $0.77,95 \% \mathrm{CI}: 0.42-1.39, \mathrm{p}=0.386$ ). Time to hCG normalization $\geq 10$ weeks (ORa: $0.58,95 \% \mathrm{CI}: 0.43-1.08, \mathrm{p}=0.071$ ) or time to remission with chemotherapy $\geq 14$ weeks (ORa: 0.60, 95\% CI: 0.43-1.09, $\mathrm{p}=0.067$ ) did not significantly differ among HC users when compared to patients using BM, when controlling for other risk factors using multivariate logistic regression.

Conclusions. The use of HC during postmolar follow-up or GTN treatment does not seem to increase the risk of GTN or its severity and does not postpone the normalization of hCG levels.

(C) 2017 Elsevier Inc. All rights reserved.

\footnotetext{
* Corresponding author at: Department of Obstetrics and Gynecology, Maternity Schoo of Rio de Janeiro Federal University, 180 Laranjeiras St, Rio de Janeiro, RJ 22240-000, Brazil.

E-mail address: bragamed@yahoo.com.br (A. Braga).
}

\section{Introduction}

Molar pregnancy is a reproductive anomaly that affects 1 in 200-400 pregnant women in Brazil [1], an incidence 5 to 10 times higher than in 
the United States and Europe [2,3]. This disease may present as either of two different clinical and cytogenetic forms, characterized by complete hydatidiform mole (CHM) and partial hydatidiform mole (PHM), which represent the benign spectrum of gestational trophoblastic disease (GTD) [4].

The clinical importance of molar pregnancy is the risk of progression to gestational trophoblastic neoplasia (GTN), the malignant form of GTD, that occurs in about 15-20\% of women following CHM and 1-5\% of women after PHM [2-4]. The main strategy to diagnose GTN is to evaluate the levels of human chorionic gonadotropin (hCG) in the postmolar follow-up. The increase of hCG levels over two consecutive weeks, or a plateau (changes $<10 \%$ ) for three consecutive weeks confirms the progression of molar pregnancy into GTN [5]. Fortunately, the early treatment of GTN achieves cure in $>98 \%$ of cases, even with the presence of multiple metastases $[1,6]$.

To maintain the reliability of hCG as a biological marker for GTN, including making the initial diagnosis of GTN, monitoring the response to chemotherapy, and surveilling for recurrent GTN after chemotherapy (which happens in $3 \%$ of patients with low risk GTN and in $7-10 \%$ of patients with high risk GTN), patients are advised to avoid pregnancy during the postmolar follow-up. In general, this means until 6 months after hCG level normalization without a diagnosis of GTN and until 12 months after the last cycle of chemotherapy if a patient requires GTN treatment [7-9].

Despite the World Health Organization (WHO) guidelines which maintain that the use of hormonal contraception (HC) does not increase the risk of postmolar GTN or retard hCG normalization [10], some medical associations such as the Royal College of Obstetricians and Gynaecologists [11] and the Royal Australian and New Zealand College of Obstetricians and Gynaecologists [12] have concerns about initiating HC after molar evacuation, when hCG levels are still high. This concern is based on studies from the 1970s, which suggested that the use of HC increased the risk for postmolar GTN and postponed hCG normalization [13-15]. However, the contemporary relevance of those studies has been questioned, as patients at that time used contraception with higher hormonal levels than today [16].

Although many studies about the impact of $\mathrm{HC}$ in patients with molar pregnancy and the risk of postmolar GTN attest to its safety [16-27], a recent metanalysis compiling all data on contraception in this population has shown that fewer than 800 patients with molar pregnancy using $\mathrm{HC}$ were effectively evaluated for the risks of this contraceptive method [16]. In the largest single study about this subject, although it included 2777 patients with CHM, only 154 were using HC, which sustains the concern about the use of HC immediately after molar evacuation [27]. It is also important to highlight that none of these previous studies evaluated the effect of different compositions or hormonal doses, or even the impact of confounding risk factors for GTN on their results, maintaining uncertainty about the safety of HC among women with molar pregnancy and postmolar GTN.

Therefore, the aim of this paper is to evaluate the potential influence of HC on the occurrence and clinical aggressiveness of GTN as well as the time for hCG normalization controlling for risk factors for GTN among Brazilian women with molar pregnancy. We also wanted to evaluate specifically the safety of $\mathrm{HC}$, analyzing not only its formulations, but also the impact of different dosages when compared to the patients using barrier methods of contraception (BM).

\section{Patients and methods}

\subsection{Study design}

This is a retrospective cohort study of patients with molar pregnancy followed at the Rio de Janeiro Trophoblastic Disease Center (33a Maternity Ward of Santa Casa da Misericórdia in Rio de Janeiro, Antonio Pedro University Hospital of Fluminense Federal University and Maternity
School of Rio de Janeiro Federal University) between January 2005 and January 2015.

The local Institutional Review Board approved this study under the protocol number 1.842 .895 .

\subsection{Patients}

The participants in this study were women diagnosed with molar pregnancy, confirmed by histopathology and/or immunohistochemistry [28], that exclusively used HC or BM throughout the post-molar pregnancy hCG surveillance or postmolar GTN follow-up. All patients included in this study were followed until remission and then underwent hCG surveillance for 6 months in cases of molar pregnancy with spontaneous remission or for 12 months after the end of chemotherapy for cases of postmolar GTN.

Patients were classified according to the contraceptive method into one of the following groups: BM (barrier method - male/female condom); progestin-only (PO), which included women using oral desogestrel 75 mcg used continuously or injection intramuscularly of medroxyprogesterone acetate $150 \mathrm{mg}$ every three months; combined oral contraception (COC) such as ethinyl estradiol $15 \mathrm{mcg}+$ gestodeno ( $\triangle 15$-norgestrel) $75 \mathrm{mcg}$ (EE 15), ethinyl estradiol $20 \mathrm{mcg}+$ gestodeno $75 \mathrm{mcg}$ (EE 20), ethinyl estradiol $30 \mathrm{mcg}+$ gestodeno $75 \mathrm{mcg}$ (EE 30) or ethinyl estradiol $35 \mathrm{mcg}+$ cyproterone acetate $2 \mathrm{mg}$ (EE 35), taken daily orally every 21 days, with a 7 day interval and subsequent resumption; or injection intramuscularly of combined contraception containing estradiol valerate $5 \mathrm{mg}+$ norethisterone (norethindrone) enanthate $50 \mathrm{mg}$ every month. All contraceptive methods were distributed free of charge to the patients during the entire postmolar or GTN followup and their prescriptions were validated according to the WHO medical eligibility criteria [10].

The following patients were excluded from this study: incomplete medical records (58 patients), lost to follow-up (38 patients), used another contraceptive method (78 patients), switched contraceptive method for some medical reason or personal desire (113 patients), started hormonal contraception $>7$ days after uterine evacuation ( 8 patients) or had histopathological diagnosis of placental site trophoblastic tumor (PSTT) or epithelioid trophoblastic tumor (ETT) (9 patients).

\subsection{Postmolar follow-up}

Once diagnosed with molar pregnancy, patients underwent uterine evacuation, ideally by suction curettage. A systematic postmolar follow-up was performed with weekly serum hCG measurement using the DPC Immulite ${ }^{\circledR}$ from Siemens throughout the study period. The remission of molar pregnancy or postmolar GTN was defined as three consecutive weekly hCG levels with values $<5$ IU/L [29]. Patients with molar pregnancy were followed with weekly hCG levels until normal for 3 consecutive weeks and then monthly until normal for 6 consecutive months. Patients with GTN were followed with weekly hCG levels until normal for 3 consecutive weeks and then monthly until normal for 12 consecutive months [1-3].

\subsection{Diagnosis, staging, risk factors and treatment of GTN}

We used the criteria established by the International Federation of Gynecology and Obstetrics (FIGO) 2000 for GTN diagnosis [5]. Before initiating chemotherapy, patients underwent metastatic screening for staging of GTN (stage I - disease confined to the uterus, II - involvement of the pelvic organs, III - presence of pulmonary metastasis, IV - occurrence of metastasis in other organs, notably liver and brain), as well as the FIGO/WHO prognostic risk score for chemoresistance [5]. Patients with stages I, II, and III low risk GTN (FIGO/WHO score $\leq 6$ ) were treated with single agent chemotherapy using methotrexate (MTX/FA) $1 \mathrm{mg} / \mathrm{kg}$ intramuscularly on days $1,3,5,7$ with rescue of folinic acid $0.1 \mathrm{mg} / \mathrm{kg}$ orally on days $2,4,6,8$ or actinomycin-D (Act-D) $1.25 \mathrm{mg} / \mathrm{m}^{2}$ 
intravascular every two weeks. In cases of chemoresistance to single agents, or in cases of stages II and III high risk GTN (FIGO/WHO score $\geq 7$ ) or stage IV, the EMA/CO regimen (etoposide, MTX/FA, Act-D, cyclophosphamide, vincristine) or EP/EMA (etoposide, cisplatin, MTX/FA, Act-D) were used [8].

\subsection{Variables}

The following patient variables were collected: age (in years), gravidity, parity, gestational age at diagnosis of molar pregnancy (in weeks), clinical symptomatology at presentation (anemia - defined as hemoglobin $<9 \mathrm{~g} / \mathrm{dL}$, hemorrhage, enlarged uterus for gestational age - defined as the uterine size $>4 \mathrm{~cm}$ greater than expected for gestational age, theca lutein cysts - defined as a cystic ovarian mass $>6 \mathrm{~cm}$ evaluated by pelvic-transvaginal ultrasonography, pre-eclampsia defined as blood pressure levels higher than a systolic of $140 \mathrm{~mm} \mathrm{Hg}$ and/or diastolic of $90 \mathrm{~mm} \mathrm{Hg}$ in the presence of proteinuria, hyperemesis, hyperthyroidism - defined as the serum thyroid stimulating hormone $<0.03 \mathrm{mU} / \mathrm{L}$ and serum free T4 $>1.6 \mathrm{ng} / \mathrm{dL}$ ) [30], the hCG preevacuation level (IU/L), the mode of uterine evacuation (vacuum aspiration, curettage or misoprostol for cases of PHM with fetus of gestational age over 12 weeks), the histology of the molar pregnancy (CHM or PHM), and the time for remission (in weeks) after molar pregnancy and GTN.

The development of postmolar GTN, metastatic GTN, FIGO/WHO risk score, the type of chemotherapy to achieve remission (single agent or multiagent regimen) and occurrence of pregnancy during postmolar follow-up or during GTN follow-up were also evaluated.

\subsection{Statistical analysis}

For the description of the characteristics of the population of this study, the central tendency (mean and median) and dispersion (standard deviation and maximum and minimum values) were presented for the continuous variables according to the contraceptive method (HC or BM). The comparison of the variables studied according to the contraceptive method was performed using a Student's t-test (parametric analyses). For the categorical variables, Chi-Square Test and Fisher's Exact Test comparisons between percent differences were performed when appropriate. For the continuous variables, the Shapiro-Wilk test was used to verify the normality of the distribution. Mean differences were assessed using Student's t-test for variables with normal distributions and non-parametric Mann-Whitney $U$ test when data were not normally distributed.

The crude odds ratio (ORc) and the adjusted odds ratio (ORa) with 95\% confidence intervals (95\% CI) were calculated for the occurrence of postmolar GTN in the study population. The variables that presented a level of statistical significance $(\mathrm{p}<0.05)$ using the Wald test for logistic regression were maintained in the adjusted model, evaluated by the Akaike Information Criteria (AIC).
All statistical analyzes were performed using the R statistical package (R Foundation for Statistical Computing, Vienna, Austria).

\section{Results}

The flow diagram in Fig. 1 illustrates the derivation of the study population. In total, 2828 patients were included in the final analysis, with 148 (5\%) patients in the barrier method group and 2680 (95\%) patients in the HC group.

Table 1 shows the demographic characteristics of patients with molar pregnancy according to contraception type. Rates of progression to GTN were similar among BM users when compared to those using HC ( $14.9 \%$ versus $12.9 \%, \mathrm{p}=0.500$ ), respectively. Patients using HC experienced a significantly shorter time to spontaneous remission (9.3 versus 10.4 weeks, $\mathrm{p}<0.001$ ), as well as lower occurrence of pregnancy during postmolar follow-up $(0.2 \%$, versus $3.3 \%, \mathrm{p}<0.001)$ or post-GTN follow-up ( 0 versus $9.1 \%, \mathrm{p}<0.001$ ).

To evaluate the potential confounding of HC effects by other GTN risk factors, we performed a multivariate logistic regression (Table 2). Results were adjusted for the patients' age, pre-evacuation hCG level $\geq 100,000 \mathrm{IU} / \mathrm{L}$, anemia, and histology of hydatidiform mole, based on the factors that appeared to be significant independent risk factors for development of postmolar GTN in the population studied, as shown in Supplemental Table 1. This showed that $\mathrm{HC}$ had no significant influence on the risk of postmolar GTN (ORa: 0.66, 95\% CI: 0.24-1.12, p = 0.060) or time to spontaneous remission $\geq 10$ weeks (ORa: $0.58,95 \% \mathrm{CI}: 0.43-$ $1.08, \mathrm{p}=0.071$ ). In addition, among women developing postmolar GTN, use of HC had no association with the clinical aggressiveness of postmolar GTN, such as occurrence of metastatic disease (ORa: 0.69, 95\% CI: 0.29-1.10, p = 0.598), high risk GTN (ORa: 1.10, 95\% CI: 0.80$1.43, \mathrm{p}=0.411$ ), need of multiagent chemotherapy treatment (ORa: $0.68,95 \% \mathrm{CI}: 0.30-1.09, \mathrm{p}=0.101)$, or time to remission after chemotherapy $\geq 14$ weeks (ORa: $0.60,95 \% \mathrm{CI}: 0.43-1.09$, $\mathrm{p}=0.067$ ). However, there was a lower chance of pregnancy occurring during postmolar follow-up (ORa: 0.10, 95\% CI: 0.09-0.51, p < 0.001) or during chemotherapeutic treatment (ORa: 0.08, 95\% CI: 0.04-0.31, p < 0.001) among women who used HC compared to those who used BM. We next assessed whether there were any differences in outcome associated with HC type. Even when comparing different $\mathrm{HC}$ formulations, whether PO (ORa: $1.33,95 \%$ CI: $0.79-2.24, p=0.288$ ) or COC (ORa: $0.54,95 \%$ CI: $0.29-1.01, \mathrm{p}=0.060$ ), or by independent dosages of EE: $15 \mathrm{mcg}$ (ORa: 0.50, 95\% CI: 0.27-1.01, p = 0.060), 20 mcg (ORa: 1.02, 95\% CI: 0.64-1.65, p = 0.901), 30 mcg (ORa: 1.17, 95\% CI: 0.78-1,75, p = 0.437 ) or $35 \mathrm{mcg}$ (ORa: $0.77,95 \% \mathrm{CI}: 0.42-1,39, \mathrm{p}=0.386$ ), multivariate logistic regression showed that $\mathrm{HC}$ had no significant influence on the risk of postmolar GTN when compared with BM, as presented in Supplemental Table 2.

Finally, we assessed whether HC was associated with any differences in patient clinical outcome. Table 3 presents the clinical and therapeutic outcome of patients with molar pregnancy and postmolar GTN, according to the type of $\mathrm{HC}$ used. When comparing the results of patients with

3,132 patients with molar pregnancy initially assessed

\begin{tabular}{|c|c|c|}
\hline 58 patients with incomplete medical records \\
\hline 8 patients started hormonal contraceptive late \\
\hline 2,828 patients with molar pregnancy included in this study \\
\hline 148 patients used barrier methods \\
\hline
\end{tabular}

Fig. 1. Flow diagram summarizing the derivation of the study population. 
Table 1

Characteristics of the study population according to method of contraception.

\begin{tabular}{|c|c|c|c|}
\hline \multirow[t]{2}{*}{ Variables } & \multirow{2}{*}{$\frac{\text { Barrier methods }(\mathrm{N}=148)}{\text { Mean }(\mathrm{SD}) / \text { median (range) or } \mathrm{N}(\%)}$} & \multirow{2}{*}{$\frac{\text { Hormonal contraception }(\mathrm{N}=2680)}{\text { Mean }(\mathrm{SD}) / \text { median (range) or } \mathrm{N}(\%)}$} & \multirow[t]{2}{*}{ p-Value } \\
\hline & & & \\
\hline Age $\left(\right.$ years) ${ }^{a}$ & $29.1(14.9) / 25(12-59)$ & $25.7(7.3) / 25(12-51)$ & 0.006 \\
\hline \multicolumn{3}{|l|}{ Group age (years) ${ }^{b}$} & $<\mathbf{0 . 0 0 1}$ \\
\hline$\leq 19$ & $64(43.2 \%)$ & $641(23.9 \%)$ & \\
\hline $20-39$ & $29(19.6 \%)$ & $1935(72.2 \%)$ & \\
\hline$\geq 40$ & $55(37.2 \%)$ & $104(3.9 \%)$ & \\
\hline Gravidity $^{\mathrm{a}}$ & $2.5(2.1) / 1(1-15)$ & $2.0(1.3) / 2(1-16)$ & 0.020 \\
\hline \multicolumn{3}{|l|}{ Number of gestations (group) ${ }^{b}$} & $<0.001$ \\
\hline 1 gestation & $76(51.4 \%)$ & $1213(45.3 \%)$ & \\
\hline 2 gestation & $17(11.5 \%)$ & $741(27.6 \%)$ & \\
\hline 3 or more gestation & $55(37.2 \%)$ & $726(27.1 \%)$ & \\
\hline Parity $^{\mathrm{a}}$ & $1.0(1.7) / 0(0-8)$ & $0.8(1.0) / 0(0-10)$ & 0.133 \\
\hline \multicolumn{3}{|l|}{ Parity (group) ${ }^{\mathrm{b}}$} & $<0.001$ \\
\hline Nullípara & $90(60.8 \%)$ & $1387(51.8 \%)$ & \\
\hline Primípara & $19(12.8 \%)$ & $750(28.0 \%)$ & \\
\hline Multípara & $39(26.4 \%)$ & $543(20.3 \%)$ & \\
\hline Gestational age at diagnosis (weeks) $^{\mathrm{a}}$ & $10.5(2.3) / 11(6-24)$ & $11.0(3.1) / 11(4-42)$ & 0.028 \\
\hline Proporation gestational age $\geq 10$ weeks ${ }^{\mathrm{b}}$ & $101(68.2 \%)$ & $1749(65.3 \%)$ & 0.458 \\
\hline hCG preevacuation $(\mathrm{UI} / \mathrm{L})^{\mathrm{a}}$ & $235,315.4(357,386.7) / 116,096(1165-2,190,600)$ & $273,009.1(902,206.8) / 125,215(323-4,120,000)$ & 0.613 \\
\hline \multirow{2}{*}{\multicolumn{3}{|c|}{$\begin{array}{l}\text { Histology } \\
\text { Hib }\end{array}$}} & 0.756 \\
\hline & & & 0.001 \\
\hline Complete mole & $128(86.5 \%)$ & $1999(74.6 \%)$ & \\
\hline Partial mole & $20(13.5 \%)$ & $681(25.4 \%)$ & \\
\hline \multicolumn{4}{|l|}{ Clinical symptoms } \\
\hline Anemia ${ }^{\mathrm{b}}$ & $5(3.4 \%)$ & $202(7.5 \%)$ & 0.059 \\
\hline Hemorrhage $^{\mathrm{b}}$ & $92(62.2 \%)$ & $1634(61.0 \%)$ & 0.772 \\
\hline Enlarged uterus for gestational age $\mathrm{e}^{\mathrm{b}}$ & $35(23.6 \%)$ & $661(24.7 \%)$ & 0.780 \\
\hline Theca lutein cysts ${ }^{\mathrm{b}}$ & $15(10.1 \%)$ & $339(12.6 \%)$ & 0.368 \\
\hline Preeclampsia ${ }^{\mathrm{c}}$ & $8(5.4 \%)$ & $70(2.6 \%)$ & 0.063 \\
\hline Hyperemesis ${ }^{\mathrm{b}}$ & $33(22.3 \%)$ & $571(21.3 \%)$ & 0.775 \\
\hline Hyperthyroidism ${ }^{c}$ & $1(0,7 \%)$ & $41(1.5 \%)$ & 0.724 \\
\hline \multicolumn{3}{|l|}{ Mode of uterine evacuation ${ }^{\mathrm{b}}$} & 0.240 \\
\hline Vacuum aspiration & $136(91.9 \%)$ & $2506(93.5 \%)$ & \\
\hline Curettage & $11(7.4 \%)$ & $129(4.8 \%)$ & \\
\hline Misoprostol & $1(0.7 \%)$ & $45(1.7 \%)$ & \\
\hline Time to spontaneous remission (weeks) $)^{\mathrm{a}, \mathrm{d}}$ & $10.4(2.9) / 10(6-20)$ & $9.3(3.1) / 9(0-42)$ & $<0.001$ \\
\hline Occurrence of postmolar GTN ${ }^{\mathrm{b}}$ & $22(14.9 \%)$ & $347(12.9 \%)$ & 0.500 \\
\hline Time to remission after GTN (weeks) ${ }^{a, e}$ & $14.8(4.2) / 15(9-23)$ & $13.6(3.4) / 13(6-27)$ & 0.103 \\
\hline Metastatic disease (stage II, III or IV) c,e $^{\mathrm{c}}$ & $4(18.2 \%)$ & $63(18.2 \%)$ & 1.000 \\
\hline High risk GTN (FIGO score $\geq 7)^{\mathrm{c}, \mathrm{e}}$ & $1(4.5 \%)$ & $18(5.2 \%)$ & 1.000 \\
\hline Multiagent chemotherapy treatment ${ }^{\mathrm{c}, \mathrm{e}}$ & $4(18.2 \%)$ & $45(13.0 \%)$ & 0.516 \\
\hline Pregnancy during postmolar follow-up ${ }^{c}$ & $5(3.3 \%)$ & $6(0.2 \%)$ & $<\mathbf{0 . 0 0 1}$ \\
\hline Pregnancy during GTN follow-up ${ }^{c}$ & $2(9,1 \%)$ & $0(0.0 \%)$ & $<0.001$ \\
\hline \multicolumn{4}{|l|}{ a Test $t$ for parametric distribution. } \\
\hline \multicolumn{4}{|l|}{ b Chi-Square Test. } \\
\hline \multicolumn{4}{|l|}{ c Fisher's Exact Test. } \\
\hline d For no occurrence of & & & \\
\hline
\end{tabular}

molar pregnancy using BM with PO or COC in different dosages of EE, the only significant difference observed was the lower occurrence of pregnancy during postmolar follow-up and GTN treatment. It is noteworthy that the different doses of EE had no significant impact on the occurrence of postmolar GTN or on its clinical aggressiveness.

\section{Discussion}

This study indicates that there is no significant association between the use of modern $\mathrm{HC}$ and the development of postmolar GTN. This is in agreement with some prior reports, however, previous studies failed to

Table 2

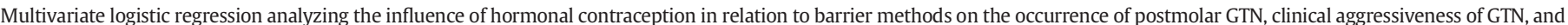
time to hCG remission.

\begin{tabular}{|c|c|c|c|c|}
\hline \multirow[t]{2}{*}{ Variables } & \multicolumn{4}{|c|}{ Hormonal contraception } \\
\hline & OR crude $(95 \% \mathrm{CI})$ & p-Value ${ }^{a}$ & OR adjusted crude $(95 \% \mathrm{CI})$ & p-Value ${ }^{a}$ \\
\hline Occurrence of postmolar GTN & $0.85(0.53-1.36)$ & 0.501 & $0.66(0.24-1.12)$ & 0.060 \\
\hline Metastatic disease (stage II, III or IV) & $0.89(0.58-1.24)$ & 0.512 & $0.69(0.29-1.10)$ & 0.598 \\
\hline High risk GTN (FIGO score $\geq 7$ ) & $1.02(0.78-1.35)$ & 0.391 & $1.10(0.80-1.43)$ & 0.411 \\
\hline Multiagent chemotherapy treatment & $0.71(0.36-1.19)$ & 0.331 & $0.68(0.30-1.09)$ & 0.101 \\
\hline Time to spontaneous remission $\geq 10$ weeks & $0.65(0.45-1.12)$ & 0.080 & $0.58(0.43-1.08)$ & 0.071 \\
\hline Pregnancy during postmolar follow-up & $0.12(0.4-0.45)$ & $<0.001$ & $0.10(0.09-0.51)$ & $<0.001$ \\
\hline Time to remission after chemotherapy $\geq 14$ weeks & $0.65(0.45-1.15)$ & 0.079 & $0.60(0.43-1.09)$ & 0.067 \\
\hline Pregnancy during GTN follow-up & $0.10(0.06-0.35)$ & $<0.001$ & $0.08(0.04-0.31)$ & $<0.001$ \\
\hline
\end{tabular}

Adjusted by Age group, hCG preevacuation $\geq 100,000$ (IU/L), anemia and histology of hydatidiform mole.

a Wald test for logistic regression. 
Table 3

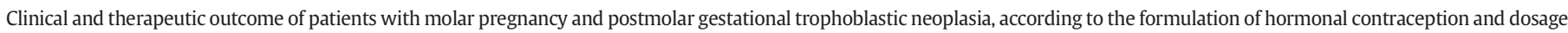
of Ethinyl estradiol present in combined oral hormonal contraception, in relation to barrier methods.

\begin{tabular}{|c|c|c|c|c|c|c|}
\hline \multirow[t]{2}{*}{ Variables } & \multirow{2}{*}{$\begin{array}{l}\text { Barrier methods } \\
\mathrm{N}=148\end{array}$} & \multirow{2}{*}{$\frac{\text { Progestin only }}{\mathrm{N}=622}$} & \multicolumn{4}{|c|}{ Combined oral hormonal contraception $\mathrm{N}=1674$} \\
\hline & & & $15 \mathrm{mcg}$ EE N $=339$ & $20 \mathrm{mcg}$ EE N $=382$ & $30 \mathrm{mcg}$ EE N $=760$ & $35 \mathrm{mcg}$ EE N $=133$ \\
\hline Postmolar GTN ${ }^{\mathrm{a}}$ & $22(14.9 \%)$ & $103(16.6 \%)$ & $62(15.5 \%)$ & $37(9.7 \%)$ & $86(11.3 \%)$ & $20(15.0 \%)$ \\
\hline p-Value & & 0.615 & 0.846 & 0.089 & 0.222 & 0.968 \\
\hline Time to spontaneous remission (weeks) ${ }^{\mathrm{c}, \mathrm{e}}$ & $\begin{array}{l}10.4(2.9) / 10 \\
(6-20)\end{array}$ & $\begin{array}{l}8.6(2.1) / 9 \\
(0-18)\end{array}$ & $\begin{array}{l}8.8(2.6) / 9 \\
(5-18)\end{array}$ & $\begin{array}{l}9.6(3.8) / 9 \\
(0-42)\end{array}$ & $\begin{array}{l}9.8(3.2) / 9 \\
(0-22)\end{array}$ & $\begin{array}{l}9.7(4.5) / 9 \\
(4-27)\end{array}$ \\
\hline p-Value & & 0.060 & 0.078 & 0.189 & 0.090 & 0.097 \\
\hline Pregnancy during postmolar follow-up ${ }^{\mathrm{b}}$ & $5(3.3 \%)$ & $0(0.0 \%)$ & $2(0.5 \%)$ & $2(0.5 \%)$ & $2(0.2 \%)$ & $0(0.0 \%)$ \\
\hline p-Value & & $<0.001$ & 0.056 & 0.055 & 0.040 & 0.059 \\
\hline Metastatic disease (stage II, III or IV) $)^{\mathrm{b}, \mathrm{f}}$ & $4(18.2 \%)$ & $17(16.5 \%)$ & $7(11.3 \%)$ & $13(35.1 \%)$ & $12(14.0 \%)$ & $5(25.0 \%)$ \\
\hline $\mathrm{p}$-Value & & 0.764 & 0.467 & 0.237 & 0.737 & 0.714 \\
\hline High risk GTN (FIGO score $\geq 7$ ) & $1(4.5 \%)$ & $6(5.8 \%)$ & $6(9.7 \%)$ & $3(8.1 \%)$ & $2(2.3 \%)$ & $1(5.0 \%)$ \\
\hline p-Value & & 1.000 & 0.670 & 1.000 & 0.499 & 1.000 \\
\hline Multiagent chemotherapy treatment $\mathrm{t}^{\mathrm{b}, \mathrm{f}}$ & $4(18.2 \%)$ & $16(15.5 \%)$ & $8(12.9 \%)$ & $5(13.5 \%)$ & $11(12.8 \%)$ & $0(0.0 \%)$ \\
\hline p-Value & & 0.759 & 0.504 & 0.715 & 0.502 & 0.109 \\
\hline Time to remission after GTN (weeks) ${ }^{\mathrm{d}, \mathrm{f}}$ & $\begin{array}{l}14.8(4.2) / 14.5 \\
(9-23)\end{array}$ & $\begin{array}{l}13.4(2.7) / 13 \\
(6-20)\end{array}$ & $\begin{array}{l}13.5(2.3) / 13 \\
(7-21)\end{array}$ & $\begin{array}{l}13.6(4.2) / 13 \\
(7-25)\end{array}$ & $\begin{array}{l}15.8(3.6) / 15 \\
(10-27)\end{array}$ & $\begin{array}{l}14.6(3.4) / 14 \\
(8-20)\end{array}$ \\
\hline p-Value & & $0.061^{\mathrm{d}}$ & 0.060 & 0.060 & 0.245 & 0.823 \\
\hline Pregnancy during GTN follow-up ${ }^{\mathrm{b}}$ & $2(9.1 \%)$ & $0(0.0 \%)$ & $0(0.0 \%)$ & $0(0.0 \%)$ & $0(0.0 \%)$ & $0(0.0 \%)$ \\
\hline p-Value & & 0.032 & 0.005 & 0.005 & 0.007 & 0.007 \\
\hline
\end{tabular}

a Pearson Chi-Square test.

b Fisher's Exact Test.

c Test $\mathrm{t}$.

d Mann-Whitney $U$ test.

e No occurrence of postmolar GTN: barrier methods $=126$ patients, progestin-only $=519$ patients and combined oral hormonal contraception 1469 patients ( 15 mcg EE $=337$ patients, $20 \mathrm{mcg} \mathrm{EE}=345$ patients, $30 \mathrm{mcg} \mathrm{EE}=674$ patients and $35 \mathrm{mcg} \mathrm{EE}=113$ patients $)$.

${ }^{\mathrm{f}}$ Occurrence of postmolar GTN: barrier methods $=22$ patients, progestin-only $=103$ patients and combined oral hormonal contraception 205 patients $(15 \mathrm{mcg}$ EE $=62$ patients, 20 mcg $\mathrm{EE}=37$ patients, $30 \mathrm{mcg} \mathrm{EE}=86$ patients and $35 \mathrm{mcg} \mathrm{EE}=20$ patients $)$

control for GTN risk factors [16-27]. Controlling for underlying GTN risk factors is important. Patients using BM included in our study had two well-recognized high risk factors for progression to GTN, namely advanced maternal age ( 29.1 versus 25.7 years, $\mathrm{p}=0.006$ ), with more than one-third of patients over 40 years (37.2\% versus $3.9 \%, p=0.020$ ), and a higher occurrence of CHM (86.5\% versus $74.6 \%, \mathrm{p}=0.001$ ), when compared to patients using HC. Unlike previous studies, we controlled for these risk factors for postmolar GTN and therefore, our results likely represent a more accurate assessment of $\mathrm{HC}$ and its relationship to the natural history of postmolar GTN [32,33].

Rather than finding a relationship between HC and a higher risk of postmolar GTN or a delayed time interval for spontaneous hCG remission, instead we found a trend for a reduced risk for postmolar GTN $(\mathrm{p}=0.060)$. While this did not quite reach statistical significance, the result is consistent with other studies [19,20,22,24]. We also found a similar trend for an association between $\mathrm{HC}$ and a reduced time interval for hCG remission (0.067), similar to a study by Morrow et al. [19]. A larger data set may be powered to assess these differences.

This investigation adds to the literature that HC does not significantly influence the development of postmolar GTN regardless of hormonal formulations (combined $\mathrm{HC}$ or PO) or dose of EE present in the $\mathrm{COC}$ (15 mcg, $20 \mathrm{mcg}, 30 \mathrm{mcg}$ or $35 \mathrm{mcg}$ ). In addition, this study reinforces that the use of HC does not postpone the time for hCG normalization and represents a superior way to prevent pregnancies during follow up of molar pregnancy or postmolar GTN.

This study has two main limitations that should be highlighted: its retrospective design, the lack of randomization of patients to use different contraceptive methods and the unavoidable vast imbalance in the numbers of patients receiving HC (2680) versus BM (148). To minimize the effects of study design, we sought to include as many patients with the same hormone combinations on COC. Nevertheless, this is the largest study on this subject, especially among patients using $\mathrm{HC}$ after molar pregnancy. This allowed us to evaluate the influence of varied hormonal formulations (combined $\mathrm{HC}$ or $\mathrm{PO}$ ) and different dosages of EE in COCs in the follow-up of patients with molar pregnancy or postmolar GTN.

Our study also highlights the superior contraceptive efficacy of HC compared to BM for women undergoing hCG surveillance. To avoid unintended pregnancy during postmolar follow-up, patients should receive prompt and accurate contraceptive advice [1-3]. The use of BM or $\mathrm{HC}$ is allowed for patients with molar pregnancy and must be started soon after uterine evacuation [31]. Despite the thorough contraceptive advice provided in Reference Centers for GTD, about $12-23 \%$ of the patients become pregnant before discharge from postmolar follow-up or during chemotherapy for GTN $[9,34,35]$. This study shows that the rates of pregnancies among women using BM are substantially higher than those using HC, unequivocally showing the advantages of $\mathrm{HC}$ for patients with molar pregnancy and postmolar GTN [24].

Certainly, the most important aspect of this investigation is to evaluate the relationship between the use of HC during postmolar followup and the development of GTN. Our findings are notably different from Stone et al., who found a higher OR for postmolar GTN among users of HC (OR: 1.19, 95\% CI: 1.12-3.22, p < 0.001) [13]. However, this study from 1976 used diagnostic criteria for GTN different from those recommended by FIGO 2000 [5]. Thus, patients diagnosed with GTN in their study may not have met current criteria for GTN [16]. Another consideration of the study by Stone et al. concerns the dose of estrogen used in contraceptive pills in the 1970s (above $50 \mathrm{mcg}$ EE) which is considerably higher than that used in the formulations evaluated in the present study [13]. It is reasonable to question a possible dosedependent effect between HC and the risk of postmolar GTN. Yuen and Burch reported that women using high-dose $\mathrm{HC}$ were more likely to develop postmolar GTN when compared to women using low-dose HC [23]. However, among women during postmolar follow-up, our study shows the safety of using COCs with modern EE dosages, below $50 \mathrm{mcg} E \mathrm{E}$, for which there appears to be no significant difference in progression to GTN.

It is known that in certain hormone-dependent cancers (as in cases of breast cancer with receptors for sex hormones - estrogen and progesterone), $\mathrm{HC}$ is formally contraindicated [10]. There is limited evidence of safety in the use of $\mathrm{HC}$ in patients during chemotherapy for the treatment of GTN $[10,18]$. The results presented in our study show that HC did not significantly influence the occurrence of metastatic GTN, high risk GTN, the need for multiagent chemotherapy or time to remission after postmolar GTN when comparing patients using BM or HC, 
combined $\mathrm{HC}$ or PO, or even in different dosages of EE in the modern COCs. Another interesting aspect of the influence of $\mathrm{HC}$ in the postmolar follow-up is a supposed delay in spontaneous hCG remission. Investigations of the 1970s indicated that patients using $\mathrm{HC}$ required more time to normalize the hCG levels, increasing the duration of postmolar follow-up [13-15]. The only meta-analysis on this subject using modern hCG assays [16] cites that 1 of the 5 included studies demonstrated that HC users needed less time than non-HC users to normalize the hCG levels [19]. The cause of this effect is uncertain. Our results also show this interesting association (Table 1). This may represent the effects of renal senescence, with a decline in the glomerular filtration rate, which occurs in women over 40 years of age $[36,37,38]$. As the prevalence of BM among women over 40 years of age is almost 10 times higher than observed in women using HC, possibly because of clinical considerations making BM more acceptable, it may be that the longer time to hCG normalization among patients using BM, in relation to those using $\mathrm{HC}$, is due to the effects of age on renal function. However, this association disappears when the time for hCG normalization is assessed through multivariate logistic regression, nullifying the effect of the age of the patients on this variable. Therefore, we feel confident in our finding that HC does not delay hCG normalization.

\section{Conclusion}

This paper reinforces the importance of HC in the follow-up of women with molar pregnancy and postmolar GTN, due to its high contraceptive effectiveness. Furthermore, HC does not increase the occurrence of postmolar GTN, the clinical aggressiveness of GTN, or the time to spontaneous hCG remission, and these findings are not affected by varied $\mathrm{HC}$ formulations (progestin-only versus combination oral contraceptive) or varied dosages of ethinyl estradiol.

Supplementary data to this article can be found online at http://dx doi.org/10.1016/j.ygyno.2017.09.007.

\section{Disclosures}

The authors report no conflicts of interest.

\section{Funding}

This research was supported by the Carlos Chagas Filho Foundation for Research Support in the State of Rio de Janeiro/Brazil (FAPERJ) (E-26/112.070/2012) - an agency under the Brazilian Ministry of Science and Technology; and the Donald P. Goldstein MD Trophoblastic Tumor Registry Endowment and the Dyett Family Trophoblastic Disease Research and Registry Endowment. The funding agencies had no direct role in the generation of the data or manuscript.

\section{References}

[1] A. Braga, E.M. Uberti, M.C. Fajardo, M. Viggiano, S.Y. Sun, B.M. Grillo, et al., Epidemiological report on the treatment of patients with gestational trophoblastic disease in 10 Brazilian referral centers: results after 12 years since International FIGO 2000 Consensus, J. Reprod. Med. 59 (2014) 241-247.

[2] J.R. Lurain, Gestational trophoblastic disease I: epidemiology, pathology, clinical presentation and diagnosis of gestational trophoblastic disease, and management of hydatidiform mole, Am. J. Obstet. Gynecol. 203 (2010) 531-539.

[3] M.J. Seckl, N.J. Sebire, R.A. Fisher, F. Golfier, L. Massuger, C. Sessa, ESMO Guidelines Working Group, Gestational trophoblastic disease: ESMO Clinical Practice Guidelines for diagnosis, treatment and follow-up, Ann. Oncol. 24 (Suppl. 6) (2013) 39S-50S.

[4] R.S. Berkowitz, D.P. Goldstein, Current advances in the management of gestational trophoblastic disease, Gynecol. Oncol. 128 (2013) 3-5.

[5] Fédération Internationale de Gynécologie et d'Obstétrique Oncology Committee FIGO staging for gestational trophoblastic neoplasia 2000, Int. J. Gynaecol. Obstet 77 (2002) 285-287.

[6] E.I. Kohorn, Worldwide survey of the results of treating gestational trophoblastic disease, J. Reprod. Med. 59 (2014) 145-153.

[7] G. Mangili, D. Lorusso, J. Brown, J. Pfisterer, L. Massuger, M. Vaughan, et al., Trophoblastic disease review for diagnosis and management: a joint report from the International Society for the Study of Trophoblastic Disease, European Organisation for the Treatment of Trophoblastic Disease, and the Gynecologic Cancer InterGroup, Int. J. Gynecol. Cancer 24 (9 Suppl 3) (2014) 109S.

[8] A. Biscaro, A. Braga, R.S. Berkowitz, Diagnosis, classification and treatment of gestational trophoblastic neoplasia, Rev. Bras. Ginecol. Obstet. 128 (2013) 3-5.

[9] A. Braga, I. Maestá, O.C. Michelin, L.R. Delmanto, M. Consonni, M.V. Rudge, P. Belfort, Maternal and perinatal outcomes of first pregnancy after chemotherapy for gestational trophoblastic neoplasia in Brazilian women, Gynecol. Oncol. 112 (2009) 568-571.

[10] World Health Organization (WHO), Medical Eligibility Criteria for Contraceptive Use, 5th edition WHO, Geneva, 2015 Available at: External link http://who.int/ reproductivehealth/publications/family_planning/MEC-5/en/, Accessed date: 3 May 2017.

[11] Royal College of Obstetricians and Gynaecologists (RCOG), The management of gestational trophoblastic disease. Green-Top guideline n.38Available at: External link http://www.rcog.org.uk/files/rcog-corp/GT38ManagementGestational0210.pdf 2010, Accessed date: 3 May 2017.

[12] Royal Australian and New Zealand College of Obstetricians and Gynaecologists (RANZCOG), Statement for the management of gestational trophoblastic disease, https://www.ranzcog.edu.au/RANZCOG_SITE/media/RANZCOG-MEDIA/Women\% 27s\%20Health/Statement\%20and\%20guidelines/Clinical\%20-\%20Gynaecology/Management-of-Gestational-Trophoblastic-Disease-(C-Gyn-31)-New-Statement-Nov 13.pdf?ext $=$.pdf, Accessed date: 3 May 2017.

[13] M. Stone, J. Dent, A. Dardana, K.D. Bagshawe, Relationship of oral contraception to development of trophoblastic tumor after evacuation of a hydatidiform mole, Br. J. Obstet. Gynaecol. 83 (1976) 913-916.

[14] M. Stone, K.D. Bagshawe, An analysis of the influences of maternal age, gestational age, contraceptive method, and the mode of primary treatment of patients with hydatidiform moles on the incidence of subsequent chemotherapy, Br. J. Obstet. Gynaecol. 86 (1979) 782-792.

[15] K.D. Bagshawe, M. Stone, Oral contraceptives and post-molar trophoblastic tumours, Lancet 2 (1980) 1250.

[16] H.L.F.F. Costa, P. Doyle, Influence of oral contraceptives in the development of postmolar trophoblastic neoplasia - a systematic review, Gynecol. Oncol. 100 (2006) 579-585

[17] R.S. Berkowitz, D.P. Goldstein, A.R. Marean, M. Bernstein, Oral contraceptives and postmolar trophoblastic disease, Obstet. Gynecol. 58 (1981) 474-477.

[18] G.L. Eddy, J.B. Schlaerth, R.H. Natlick, O. Gaddis, R.M. Nakamura, C.P. Morrow, Postmolar trophoblastic disease in women using hormonal contraception with and without estrogen, Obstet. Gynecol. 62 (1983) 736-740.

[19] P. Morrow, R. Nakamura, J. Schlaerth, O. Gaddis, G. Eddy, The influence of oral contraceptives on the postmolar human chorionic gonadotropin regression curve, Am. J. Obstet. Gynecol. 151 (1985) 906-914.

[20] R.E. Deicas, D.S. Miller, A.W. Rademaker, J.R. Lurain, The role of contraception in the development of postmolar trophoblastic tumor, Obstet. Gynecol. 78 (1991) 221-226.

[21] A.S. Utoro, in: P.D. Lukman (Ed.), Comparison on the Need for Chemotherapy of the Hydatidiform Mole Patients Who Are Using Oral Contraceptives and Patients Who Are Not, Kongres Obstetri Ginekologie Indonesia, Indonesia: Yogyakarta 1992, pp. 590-593.

[22] G.L. Goldberg, K. Cloete, B. Bloch, K. Wiswedel, M.M. Altaras, Medroxyprogesterone acetate in non-metastatic gestational trophoblastic disease, Br. J. Obstet. Gynaecol. 94 (1987) 22-25.

[23] H.B. Yuen, C.P. Burch, Relationship of oral contraceptives and the intrauterine contraceptive devices to the regression of concentration of the beta subunit of human chorionic gonadotropin and invasive complications after molar pregnancy, Am. J. Obstet. Gynecol. 145 (1983) 214-217.

[24] S.L. Curry, J.B. Schlareth, E.I. Kohorn, J.B. Boyce, H. Gore, L.B. Twiggs, et al., Hormonal contraception and trophoblastic sequelae after hydatidiform mole (a Gynecologic Oncology Group study), Am. J. Obstet. Gynecol. 160 (1989) 805-811.

[25] I.F. Adewole, A. Oladokun, A.O. Fawole, J.F. Olawuyi, J.A. Adeleye, Fertility regulatory methods and development of complications after evacuation of complete hydatidiform mole, J. Obstet. Gynaecol. 20 (2000) 68-69.

[26] M.E. Gaffield, N. Kapp, K.M. Curtis, Combined oral contraceptive and intrauterine device use among women with gestational trophoblastic disease, Contraception 80 (2009) 363-371.

[27] A. Braga, I. Maestá, D. Short, P. Savage, R. Harvey, M.J. Seckl, Hormonal contraceptive use before hCG remission does not increase the risk of gestational trophoblastic neoplasia following complete hydatidiform mole: a historical database review, BJOG 123 (2016) 1330-1335.

[28] N.J. Sebire, Histopathological diagnosis of hydatidiform mole: contemporary features and clinical implications, Fetal Pediatr. Pathol. 29 (2010) 1-16.

[29] L.A. Cole, E.I. Kohorn, The need for an hCG assay that appropriately detects trophoblastic disease and other hCG-producing cancers, J. Reprod. Med. 51 (2006) 793-811.

[30] A. Braga, V. Moraes, I. Maestá, J. Amim Júnior, J. Rezende-Filho, K. Elias, R.S. Berkowitz, Changing trends in the clinical presentation and management of complete hydatidiform mole among Brazilian women, Int. J. Gynecol. Cancer 26 (5) (2016) 984-990.

[31] R.S. Berkowitz, D.P. Goldstein, Clinical practice. Molar pregnancy, N. Engl. J. Med. 360 (2009) 1639-1645.

[32] K.M. Elias, M. Shoni, M. Bernstein, D.P. Goldstein, R.S. Berkowitz, Complete hydatidiform mole in women aged 40 to 49 years. J. Reprod. Med. 57 (2012) 254-258.

[33] A.A. Gockley, A. Melamed, N.T. Joseph, M. Clapp, S.Y. Sun, D.P. Goldstein, N.S. Horowitz, R.S. Berkowitz, The effect of adolescence and advanced maternal age on the incidence of complete and partial molar pregnancy, Gynecol. Oncol. 140 (2016) 470-473. 
[34] L.S. Massad, N.R. Abu-Rustum, S.S. Lee, V. Renta, Poor compliance with postmolar surveillance and treatment protocols by indigent women, Obstet. Gynecol. 96 (2000) 940-944.

[35] J.E. Allen, M.R. King, D.F. Farrar, D.S. Miller, J.O. Schorge, Postmolar surveillance at a trophoblastic disease center that serves indigent women, Am. J. Obstet. Gynecol. 188 (2003) 1151-1153.

[36] L.A. Cole, S.A. Khanlian, A. Giddings, S.A. Butler, C.Y. Muller, C. Hammond, E. Kohorn, Gestational trophoblastic diseases: 4. Presentation with persistent low positive human chorionic gonadotropin test results, Gynecol. Oncol. 102 (2006) 165-172.

[37] J.A. Snyder, S. Haymond, C.A. Parvin, A.M. Gronowski, D.G. Grenache, Diagnostic considerations in the measurement of human chorionic gonadotropin in aging women, Clin. Chem. 51 (2005) 1830-1835.

[38] R.J. Glassock, C. Winearls, Ageing and the glomerular filtration rate: truths and consequences, Trans. Am. Clin. Climatol. Assoc. 120 (2009) 419-428. 